\title{
Quality of life after aortic valve surgery: Replacement versus reconstruction
}

\author{
Diana Aicher, MD, ${ }^{\mathrm{a}}$ Annika Holz, ${ }^{\mathrm{a}}$ Susanne Feldner, MD, ${ }^{\mathrm{a}}$ Volker Köllner, MD, ${ }^{\mathrm{b}}$ and \\ Hans-Joachim Schäfers, MD
}

Objective: Quality of life has been shown to be influenced by aortic valve replacement, particularly in younger patients. Aortic valve repair is a recent alternative to replacement. We investigated quality of life and anxiety and depression after aortic valve repair and compared with 2 established replacement alternatives, mechanical valve and pulmonary autograft.

Methods: In a cross-sectional study, 166 patients (age, 18-45 years) were studied after isolated elective aortic valve surgery. They had undergone aortic valve repair (group $\mathrm{I}, \mathrm{n}=86$ ), replacement with mechanical prosthesis (group II, $\mathrm{n}=41$ ), or pulmonary autograft (group III, $\mathrm{n}=39$ ). Assessment was performed by Short Form Health Survey, Hospital Anxiety and Depression Scale, Cardiac Anxiety Questionnaire, and valve-specific questions.

Results: In Short Form Health Survey, groups I and III revealed similar or identical scores better than group II in physical functioning $(P=.02)$, general health $(P=.03)$, and mental health $(P=.05)$. No differences were found in Hospital Anxiety and Depression Scale score. In cardiac anxiety, there was less heart-focused attention in groups I and III than in group II $(P=.043, P=.053)$. In response to valve-specific questions, there were no differences between groups I and III. Interestingly, fear of reoperation was identical in all 3 groups.

Conclusions: In young patients after aortic valve surgery quality of life is influenced by type of operation. Although differences are limited, aortic valve reconstruction and pulmonary autograft replacement lead to less long-term alteration from normal values. (J Thorac Cardiovasc Surg 2011;142:e19-24)

Aortic valve replacement has become the standard of care for hemodynamically severe regurgitation or stenosis of the aortic valve. ${ }^{1}$ Mechanical and biologic substitutes result in good hemodynamic relief but expose the patient to valverelated complications at a clinically relevant incidence., The pulmonary autograft is a possible alternative, particularly for young patients or those who wish to avoid long-term anticoagulation. ${ }^{4}$ Recent data suggest that the autograft is associated with a low incidence of valve-related complications. ${ }^{5}$ In the past decade, reconstructive surgery has become a new alternative in surgical treatment of aortic valve regurgitation, both for dilated and for normal roots. ${ }^{6-10}$

Currently, recommendations for a specific aortic valve procedure or substitute are based primarily on postoperative survival data. ${ }^{1}$ This assumes that the primary consideration of the patient is survival and not the incidence of valverelated complications. The relative incidence of complications and a more individualized estimate of life expectancy

\footnotetext{
From the Department of Thoracic and Cardiovascular Surgery, ${ }^{a}$ University Hospital of Saarland, Homburg/Saar, Germany; and the Department of Psychosomatic Medicine, ${ }^{\mathrm{b}}$ Mediclin Bliestal Rehabilitation Hospital, Blieskastel, Germany.

Disclosures: Authors have nothing to disclose with regard to commercial support.

Received for publication Oct 5, 2010; revisions received Jan 12, 2011; accepted for publication Feb 9, 2011; available ahead of print March 30, 2011.

Address for reprints: Hans-Joachim Schäfers, MD, Department of Thoracic and Car-

diovascular Surgery, University Hospital of Saarland, Homburg/Saar, Germany

(E-mail: h-j.schaefers@uniklinikum-saarland.de).

$0022-5223 / \$ 36.00$

Copyright (C) 2011 by The American Association for Thoracic Surgery

doi:10.1016/j.jtcvs.2011.02.006
}

have only recently been studied and recommended as guide for therapeutic decisions. ${ }^{11}$

In our experience, numerous discussions with patients before and after aortic valve operations have shown a general trend toward strongly considering the incidence of valve-related complications and also quality of life (QoL) when choosing the procedure for their aortic valves.

The effect of different aortic valve operations on postoperative QoL has been studied only more recently. It has been demonstrated that aortic valve replacement markedly improves QoL relative to the preoperative status. ${ }^{12,13}$ In several studies, no differences were found between biologic and mechanical prostheses. ${ }^{12,13}$ A comparison between QoL after implantation of a pulmonary autograft and after mechanical aortic valve replacement revealed significantly higher scores in physical QoL after autograft replacement. ${ }^{14}$

As yet there are no published data comparing QoL after aortic valve repair with that after more established alternatives. It may be assumed that patients would intuitively prefer preservation of their own valve over replacement with material from a foreign body; however, any informed consent must include the fact that the current replacement options allow a 20-year prognosis, whereas the scarcity of long-term data on aortic valve repair allow at best a 10year prognosis. In addition, the durability of repair has not always been ideal, ${ }^{15,16}$ and this knowledge may have a negative effect on QoL. On the other hand, aortic valve reconstruction has been shown to be associated with a low 


\section{Abbreviations and Acronyms \\ NYHA $=$ New York Heart Association \\ $\mathrm{QoL}=$ quality of life \\ SF-36 = German version of the Short Form Health Survey}

incidence of valve-related complications, ${ }^{17,18}$ which may contribute to a positive attitude toward this procedure.

We therefore investigated the QoL and the impact of heart-related and general anxiety and depression after aortic valve repair and compared them with those of 2 established alternatives for the young patient, replacement with a mechanical valve and replacement with a pulmonary autograft. Our hypothesis was that the absence of anticoagulation and the low incidence of valve-related complications after repair should result in a QoL comparable to that after pulmonary autograft.

\section{MATERIALS AND METHODS \\ Patients}

In a clinical cross-sectional, study patients were studied who had undergone aortic valve surgery during a 10-year interval (1997-2007) and were alive at the time of the investigation. To minimize the effect of patient age on QoL, only patients who were older than 18 and younger than 45 years were included. Patients were excluded if more than the aortic valve required surgical treatment (eg, ascending aorta, mitral valve) or if they required treatment for active endocarditis. To minimize potential effects of communication problems, only patients who spoke and understood German fluently were included.

Secondary exclusion criteria for matching were left ventricular ejection fraction less than $50 \%$, more than minimal residual aortic regurgitation, postoperative New York Heart Association (NYHA) class greater than I, the presence of a psychiatric disorder, and dialysis-dependent renal failure. These criteria led to exclusion of 4 patients who were in NYHA class II in conjunction with depressed left ventricular function; these patients also had grade II aortic regurgitation. In addition, patients with other cardiac comorbidity (eg, mitral regurgitation requiring surgery) and active endocarditis as indication for surgery were excluded $(n=13)$ to avoid interference between type of operation and other physical limitations, such as previous stroke. None of the patients underwent reoperation after the index procedure for which they were studied. A total of 6 patients were included for whom the index operation was a reoperation. Three patients underwent biologic aortic valve replacement during the study period; these patients were not included.

Only patients who gave their consent to the study and the publication of the results in anonymized fashion were included, and the institutional review board gave its approval for this investigation. Twenty-five of 191 patients refused to participate, and the remaining 166 (positive response rate $87 \%$ ) are considered in this study. Of these, 86 hade undergone aortic valve repair (group I), 41 had undergone valve replacement with a mechanical prosthesis (group II), and 39 had undergone replacement with a pulmonary autograft (group III). Patients in group II were treated with warfarin sodium-based anticoagulation; patient in groups I and III received aspirin $(100 \mathrm{mg} / \mathrm{d})$ for 6 weeks and no anticoagulation thereafter.

\section{Instruments and Assessment}

All patients were contacted directly regarding participation in the study during an outpatient visit or by telephone. They were given the questionnaires and asked to return them by mail.
Assessment of health-related QoL was performed with the German version of the Short Form Health Survey (SF-36). ${ }^{19}$ The 36 items were analyzed in 8 subscales (physical functioning, physical role, bodily pain, general health, vitality, social functioning, emotional role, and mental health).

Anxiety and depression were analyzed with the German version of the Hospital Anxiety and Depression Scale. ${ }^{20}$ The 14 items were those included in the 2 dimensions of anxiety and depression.

The patients were also assessed with the German version of the Cardiac Anxiety Questionnaire, ${ }^{21}$ consisting of 17 questions in 3 scales: fear (regarding the heart), avoidance (cardioprotective behavior, avoidance of physical exertion), and attention (awareness of heart functioning and heartbeat). Finally, valve-specific questions were asked, as published by Perchinsky and colleagues. ${ }^{13}$

In addition, preoperative hemodynamic data (type and severity of aortic valve lesion, left ventricular ejection fraction, NYHA class, left ventricular dimensions, transvalvular pressure gradients, comorbidity) were collected and analyzed. Postoperative cardiac data including NYHA class, transvalvular gradients, degree of aortic regurgitation, and left ventricular function and dimensions were collected and analyzed. Personal data included age, sex, and schooling.

\section{Statistical Analysis}

Categoric variables were described as absolute and relative frequencies and continuous variables as mean $\pm \mathrm{SD}$. The comparisons between groups were performed by Kruskal-Wallis test for categoric variables and by 2sided analysis of variance for continuous variables. The SPSS software package version 16.0 (SPSS Inc, an IBM Company, Chicago, Ill) was used.

\section{RESULTS \\ Clinical Data}

There were no significant differences between the groups with regard to sex distribution (Table 1), preoperative NYHA class, or parameters of left ventricular function. There was a significantly higher proportion of patients with preoperative aortic regurgitation in group I $(86.2 \%$ vs $65 \%$ in group II and $62.1 \%$ in group III, $P=.001$ ). Similarly, there was no difference between the groups with regard to postoperative clinical or cardiac parameters. There was a higher proportion of individuals with college education in group I $(40.2 \%$ vs $20.5 \%$ in group II and $17.9 \%$ in group III, $P=.023$ ).

In group I, the interval between operation and survey date was $2.46 \pm 2.16$ years. In groups II and III, this interval was significantly longer, at $6.48 \pm 2.38$ years and $6.07 \pm 2.59$ years, respectively.

Patients in group I were significantly younger at the time of the investigation, resulting from both slightly younger age at surgery $(P=.114)$ and shorter follow-up $(P=.08)$. To correct for the nonsignificant difference in follow-up, all analyses were repeated for a subgroup of patients with a follow-up of 3 to 7 years. This cohort included 71 patients (group I, $\mathrm{n}=27$; group II, $\mathrm{n}=22$; group III, $\mathrm{n}=22$ ).

\section{Health-Related QoL (SF-36)}

In physical functioning, group I had significantly higher scores than group II ( 88.39 vs $80.37, P=.022)$, whereas the difference between groups I and III (82.56) was not 
TABLE 1. Patient characteristics

\begin{tabular}{lcccc}
\hline & No. & $\begin{array}{c}\text { Sex } \\
\text { (male/female) }\end{array}$ & $\begin{array}{c}\text { Age at operation } \\
(\mathbf{y}, \text { mean } \pm \text { SD) }\end{array}$ & $\begin{array}{c}\text { Age at survey } \\
(\mathbf{y}, \text { mean } \pm \text { SD) }\end{array}$ \\
\hline Group I & 87 & $63: 24$ & $38 \pm 6$ & $40 \pm 6$ \\
Group II & 40 & $35: 5$ & $40 \pm 7$ & $46 \pm 7$ \\
Group III & 39 & $27: 12$ & $40 \pm 7$ & $46 \pm 7$ \\
\hline
\end{tabular}

Group I, Patients with valve repair; Group II, patients after mechanical aortic valve replacement; Group III, patients after Ross procedure.

significant ( $P=.099$; Table 2$)$. Some of the analyzed parameters were not constant but varied in relation to time elapsed since the operation. This effect was particularly apparent for the physical sum scale (Figure 1). We therefore performed an additional analysis in which only a subgroup of patients for whom the follow-up ranged from 3 to 7 years was studied. In this subgroup with more defined follow-up duration, physical functioning after repair (group I, 92.50) was significantly higher than that after mechanical replacement (group II, 80.9; $P=.01$ ) and was comparable to that in group III (85.0, $P=.089)$.

There were no difference among the 3 groups in physical role. In bodily pain, there were identical scores in groups I and III, with a trend toward higher scores than in group II, although the differences were not significant (Table 2). Only in the subgroup of patients with a follow-up of 3 to 7 years did patients who had undergone repair reveal significantly less pain than those who had undergone mechanical replacement ( 86.8 vs $72.54, P=.037$ ). With regard to general health, there was a significantly higher score in group I (66.21) than in group II $(57.67, P=.029)$, whereas the difference between groups II and III (64.86) was not significant.

In social functioning, comparable data were obtained in all 3 groups, although there was a trend toward superiority of group III relative to group II. Identical scores were seen regarding emotional role (Table 2). In mental health, group I scored better than group II $(P=.054)$, and the difference between groups III and II was also significant (63.4 vs 73.23, respectively, $P=.016$ ). Similar findings were made after correction for follow-up, although only the inferiority of mechanical replacement relative to the autograft remained significant $(P=.018)$.

\section{Anxiety and Depression (Hospital Anxiety and Depression Scale, Cardiac Anxiety Questionnaire)}

No differences were found between the groups with regard to anxiety and depression in the Hospital Anxiety and Depression Scale score (Table 3), either in the whole cohort or in the subgroup of 3 to 7 years of follow-up. Relative to age-corrected published data for healthy subjects (23), anxiety scores were higher than normal in groups I $(P=.04)$ and II $(P=.025)$, whereas the group III score was not significantly different from normal $(P=.134)$. With regard to depression, group I scored lower than agematched healthy subjects $(23, P=.038)$, whereas the differences between groups II and III and healthy control subjects were not significant or only borderline significant $(P=.193$ and $P=.055$, respectively).

In the Cardiac Anxiety Questionnaire, group II expressed significantly more fear than group III, whereas group I showed intermediate scores (Table 3). With respect to heart-focused attention, groups I and III exhibited statistically identical scores that were better than the group II score ( $P=.043$ and $P=.053$, respectively; Table 3 ). There were no significant differences in avoidance (Table 3 ). The differences were not significant after correction for follow-up.

Our patients were different from published healthy control subjects in exhibiting higher fear (group II, 1.67; $P=.008)$, lower avoidance $(1.21, P=.005)$, and higher attention (1.52, $P=.034)$. With regard to Cardiac Anxiety Questionnaire scores, they were similar to other patients who had undergone valve replacement or coronary bypass surgery, with more anxiety but less avoidance. ${ }^{22}$

With regard to the valve-specific questionnaire, there were no differences between the groups on question 1 (positive view of the decision to have undergone surgery, $P=.821$; Table 4). As expected, patients in group II were more frequently disturbed by valve sounds. Interestingly, $8.4 \%$ in group I and $7.7 \%$ in group III noted subjective disturbance by valve sounds $(P=.000)$. Patients in group II more frequently felt disturbed by follow up visits and blood tests than did those in groups I and III $(P=.011)$. There were no differences among the 3 groups in concern regarding possible complications related to the valve operation

TABLE 2. Valve-specific questions as proposed by Perchinsky and colleagues ${ }^{13}$ handed out as questionnaire

\begin{tabular}{|c|c|c|c|c|c|c|}
\hline SF-36 subscales & Group I & $P$ value I vs II & Group II & $P$ value II vs III & Group III & $P$ value I vs III \\
\hline Physical functioning & $88.39 \pm 16.21$ & .022 & $80.37 \pm 19.59$ & .594 & $82.56 \pm 20.77$ & .099 \\
\hline Role physical & $75.28 \pm 34.2$ & .960 & $75.6 \pm 36.02$ & .684 & $78.84 \pm 36.06$ & .599 \\
\hline Bodily pain & $81.04 \pm 23.28$ & .057 & $72.4 \pm 26.58$ & .180 & $79.82 \pm 24.84$ & .739 \\
\hline General health & $66.21 \pm 20.19$ & .029 & $57.67 \pm 21.74$ & .118 & $64.86 \pm 18.34$ & .733 \\
\hline Vitality & $58.82 \pm 19.58$ & .057 & $51.53 \pm 20.55$ & .049 & $60.38 \pm 18.93$ & .682 \\
\hline Social functioning & $83.67 \pm 18.5$ & .184 & $79.43 \pm 22.46$ & .093 & $86.21 \pm 22.35$ & .522 \\
\hline Role emotional & $80.84 \pm 32.0$ & .392 & $75.0 \pm 39.04$ & .979 & $75.21 \pm 39.52$ & .413 \\
\hline Mental health & $70.07 \pm 17.75$ & .054 & $63.4 \pm 18.26$ & .016 & $73.23 \pm 17.79$ & .362 \\
\hline
\end{tabular}

SF-36, German version of the Short Form Health Survey; Group I, patients with valve repair; Group II, patients after mechanical aortic valve replacement; Group III, patients after Ross procedure. 


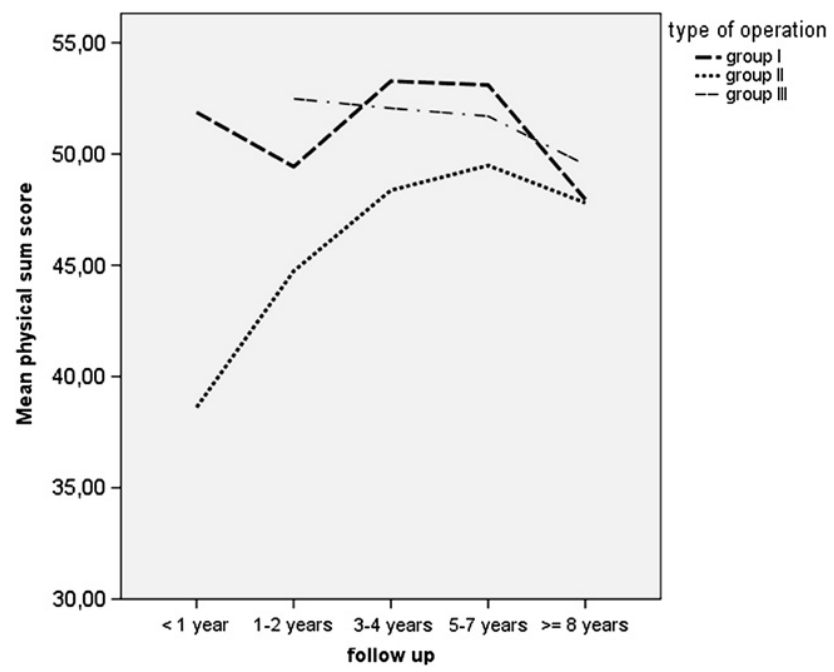

FIGURE 1. Mean physical sum scores at follow-up in patients with valve repair (group I), patients after mechanical aortic valve replacement (group II), and patients after the Ross procedure (group III).

$(P=.309)$. The possibility of bleeding related to anticoagulation was rarely a concern in groups I and III, whereas it was frequent in group II $(P=.000$; Table 4$)$. There was a significant difference in the fear of valve failure, with patients in group II more frequently afraid than those in groups I and III $(P=.036)$. With regard to the fear of requiring a repeat operation, the groups were comparable $(P=.382)$.

\section{DISCUSSION}

QoL achieved by therapeutic procedures has been receiving more attention in the last 10 years. Several studies have compared aortic valve replacement with mechanical versus biologic prostheses. ${ }^{12,13}$ The conclusion of these studies was that there was no significant difference between the 2 different types of valves, despite the need for anticoagulation after mechanical replacement. Those results stand in contrast to the findings of Nötzold and coworkers, ${ }^{14}$ who compared QoL after pulmonary autograft implantation with that after mechanical valve replacement. Nötzold and coworkers ${ }^{14}$ found significantly higher scores in physical and mental items of the SF-36, which they attributed in part to the absence of anticoagulation after pulmonary autograft implantation. The evidence, however, is less clear at a second look. The same authors published another investigation, ${ }^{22}$ in which the QoL score parameters were similar between pulmonary autograft implantation and mechanical aortic valve replacement with selfcontrolled anticoagulation.

We found similar scores in SF-36 parameters for all 3 investigated therapeutic options. QoL after all 3 was generally comparable to that published for healthy control subjects ${ }^{19}$ and to data published for recovery after valve replacement and coronary bypass surgery. ${ }^{23}$ Interestingly, our patients scored lower in symptoms of general depression than did age-matched healthy control subjects. ${ }^{24}$ This difference was significant for the patients who had undergone aortic valve reconstruction. We have also observed this phenomenon after other cardiovascular operations. It is probably related to positive readjustment of the patient after having successfully coped with a major life event, such as a cardiac operation. As expected, both general and cardiac-related levels of anxiety were increased relative to published norms. This can easily be explained by the fact that all our patients by definition had undergone the realization of vulnerability, the fact of having a life-threatening cardiac disease. It may be seen as a positive coping strategy for facing life after a valve operation, in which attention and awareness will lead to better compliance with follow up and medical recommendations. Nevertheless, QoL and heart-related anxiety as measured in this study were not as much influenced by the type of operation as we had expected.

We did, however, find some differences, mainly between mechanical valve replacement versus repair or autograft. In general, patients with mechanical valve substitutes scored lower than did those after repair or pulmonary autograft implantation. These differences were not always significant, but the trend was consistent. We can confirm the findings of Nötzold and coworkers ${ }^{14}$ and can extend them to repair. Thus our working hypothesis-that patients intuitively appreciate the absence of anticoagulation and avoidance of a foreign body, resulting in higher QoL-appears to be confirmed.

On the other hand, there were some differences between a previous investigation ${ }^{14}$ and our own. As a trend, our

TABLE 3. Means and SDs of German version of the Short Form Health Survey subscales

\begin{tabular}{lcccccc}
\hline SF-36 subscales & Group I & \multicolumn{1}{c}{$\boldsymbol{P}$ value I vs II } & Group II & $\boldsymbol{P}$ value II vs III & Group III & $\boldsymbol{P}$ value I vs III \\
\hline Hospital Anxiety and Depression Scale subscales & & & & & \\
$\quad$ Anxiety & $5.69 \pm 4.01$ & .841 & $6.75 \pm 5.07$ & .258 & $4.90 \pm 3.82$ \\
Depression & $3.69 \pm 3.25$ & .814 & $3.70 \pm 3.51$ & .265 & $2.76 \pm 2.98$ \\
Cardiac Anxiety Questionnaire subscales & & & & & \\
Fear & $1.32 \pm 0.88$ & .153 & $1.68 \pm 0.91$ & .059 & $1.14 \pm 0.73$ \\
Avoidance & $0.80 \pm 0.86$ & .264 & $1.16 \pm 0.79$ & .542 & $0.88 \pm 1.11$ \\
Attention & $1.03 \pm 0.65$ & .081 & $1.38 \pm 0.89$ & .303 & .571 \\
\hline
\end{tabular}

$P$ values are results of analysis of variance. Group I, Patients with valve repair; Group II, patients after mechanical aortic valve replacement; Group III, patients after Ross procedure. 
TABLE 4. Means and standard deviations of Hospital Anxiety and Depression Scale subscales and items

\begin{tabular}{|c|c|c|c|c|}
\hline $\begin{array}{l}\text { Valve-specific } \\
\text { questions }\end{array}$ & $\begin{array}{l}\text { Group } \\
\text { I }\end{array}$ & $\begin{array}{l}\text { Group } \\
\text { II }\end{array}$ & $\begin{array}{l}\text { Group } \\
\text { III }\end{array}$ & $\begin{array}{c}P \\
\text { value }\end{array}$ \\
\hline \multicolumn{5}{|c|}{$\begin{array}{l}\text { 1. If I had to do it over again, would I make the same decision to have } \\
\text { surgery? }\end{array}$} \\
\hline Yes & $94.0 \%$ & $89.7 \%$ & $100.0 \%$ & .821 \\
\hline I don't know & $3.6 \%$ & $7.7 \%$ & $0.0 \%$ & \\
\hline No & $2.4 \%$ & $2.6 \%$ & $0.0 \%$ & \\
\hline \multicolumn{5}{|c|}{ 2. Is there a valve sound that bothers me? } \\
\hline Never/rarely & $91.5 \%$ & $41.0 \%$ & $92.4 \%$ & $<.001$ \\
\hline Occasionally & $6.1 \%$ & $33.3 \%$ & $5.1 \%$ & \\
\hline Frequently/always & $2.4 \%$ & $25.7 \%$ & $2.5 \%$ & \\
\hline \multicolumn{5}{|c|}{$\begin{array}{l}\text { 3. Following my valve surgery, the frequency of doctor visits and blood } \\
\text { tests bothers me. }\end{array}$} \\
\hline Never/rarely & $75.9 \%$ & $61.6 \%$ & $84.2 \%$ & .011 \\
\hline Occasionally & $20.5 \%$ & $17.9 \%$ & $13.2 \%$ & \\
\hline Frequently/always & $3.6 \%$ & $20.5 \%$ & $2.6 \%$ & \\
\hline \multicolumn{5}{|c|}{ 4. The possibility of complications due to my implanted valve concerns me } \\
\hline Never/rarely & $48.2 \%$ & $48.7 \%$ & $61.5 \%$ & .309 \\
\hline Occasionally & $43.4 \%$ & $30.8 \%$ & $33.3 \%$ & \\
\hline Frequently/always & $8.4 \%$ & $20.5 \%$ & $5.2 \%$ & \\
\hline \multicolumn{5}{|c|}{$\begin{array}{l}\text { 5. I am concerned about possible bleeding caused by my anticoagulant } \\
\text { medication. }\end{array}$} \\
\hline Never/rarely & $80.5 \%$ & $43.6 \%$ & $79.5 \%$ & $<.001$ \\
\hline Occasionally & $12.2 \%$ & $15.4 \%$ & $7.7 \%$ & \\
\hline Frequently/always & $7.3 \%$ & $41.0 \%$ & $12.8 \%$ & \\
\hline \multicolumn{5}{|c|}{ 6. I am afraid that my valve may fail. } \\
\hline Never/rarely & $53.7 \%$ & $51.3 \%$ & $76.9 \%$ & .036 \\
\hline Occasionally & $34.1 \%$ & $28.2 \%$ & $17.9 \%$ & \\
\hline Frequently/always & $12.2 \%$ & $20.5 \%$ & $5.2 \%$ & \\
\hline \multicolumn{5}{|c|}{ 7. I am afraid that I may need another valve operation. } \\
\hline Never/rarely & $38.0 \%$ & $48.7 \%$ & $53.8 \%$ & .382 \\
\hline Occasionally & $45.0 \%$ & $25.6 \%$ & $25.6 \%$ & \\
\hline Frequently/always & $17.0 \%$ & $25.7 \%$ & $20.6 \%$ & \\
\hline
\end{tabular}

patients after mechanical valve replacement showed higher scores than in the previous study, whereas our patients after pulmonary autograft implantation scored lower. The reasons for these differences are not clear. One reason may be a difference in patient age; our patients were by selection younger than those studied previously. ${ }^{14}$ There is also a methodologic difference between our study and those of Nötzold and coworkers. ${ }^{14}$ They had assessed QoL through an interview according to SF-36, whereas we handed out the questionnaires to be returned later. A personal interview may be able to "sharpen" the questionnaire by modifying wordings to meet the needs of the interviewee. On the other hand, the same process may also lead to bias and skewed results. In view of the fact that the validating studies of the SF-36 form included filling out a questionnaire by the patient without interference from an interviewer, we decided to follow the validated procedure. We cannot, how- ever, rule out that misinterpretation of questions may have influenced the results.

The results of the valve-specific questionnaire were as expected and can possibly explain the differences in QoL as assessed by the SF-36. As expected, patients after mechanical aortic valve replacement more frequently reported being bothered by valve sounds, follow-up visits, fear of valve-related complications, and fear of anticoagulationrelated bleeding.

We did observe some unexpected findings from the valve-specific questions. Completely unexpected was the result that approximately $8 \%$ each in the repair and autograft groups reported that they were bothered by valve sounds. The reason can only be speculative, but possibly these patients exhibited a high degree of attention to their heart function postoperatively. Another surprising finding was that $20 \%$ of the well-informed patients were afraid of possible failure of their mechanical valve, whereas this fear was found in only $12 \%$ of patients in the repair group and 5\% of those in the autograft group. This is in strong contrast to the information given preoperatively at the time of informed consent, when the mechanical valve was described as having an excellent 40-year durability. Also surprising was the fear of a second operation, which was similar among the 3 groups, even though all were informed preoperatively that mechanical replacement was the option with the least long-term likelihood of repeat surgery. A possible explanation may be that the coping process after having undergone aortic valve surgery involves not only rational but also emotional components. In patients without a mechanical valve, anxiety may be projected into sensations involving the heart, which are misinterpreted as disturbing valve sounds. Patients with a mechanical valve could project their anxiety into fear of failure, despite rationally knowing otherwise. It remains to be clarified whether patients with these unexpected reactions exhibit more pronounced psychopathology, such as anxiety.

The results of any investigation dealing with QoL and distress after an acute event may also be influenced by duration of follow-up as an indicator of time since the operation. We found that in the first 6 to 18 months, there was a trend for patients to express higher levels of anxiety and concerns. This leveled off at 1.5 to 2 years. For this reason, we repeated the calculations for a cohort of patients with a more defined postoperative interval. A more exact determination of time-related changes would require a longitudinal comparison of the different treatment methods.

Finally, the diagnostic limitations of questionnaires also must be considered. The questions are not always understood by all individuals in identical fashion, and a questionnaire is not able to assess the effects of personality and individual expectations of the individual. To detect subtle effects, such as those induced by expectation or by the informed consent, qualitative interviews would be necessary. 
There are several limitations to our current investigation. This was not a randomized study, but rather a retrospective cross-sectional study. The preoperative condition varied among the groups, with a higher proportion of advanced academic education also seen in the repair group. This may have led to a selection bias in that patients undergoing repair had different psychologic profiles and a higher level of preoperative information. A bias through the way the informed consent was obtained cannot be ruled out, although we tried to present the same information to every patient. The patient cohorts were relatively small in relation to the expected variability in psychologic profiles. Finally, we are studying the attitude of patients toward anticoagulation in general in an ongoing research project, and there seem to be marked differences despite the same information level. This was not assessed at the time of this study. Future studies should take these aspects into consideration.

In conclusion, all 3 investigated surgical methods led to excellent QoL and limited changes in anxiety and depression relative to published data on healthy control subjects. Interestingly, the level of depression was lower than agematched published norms for all groups. Both aortic valve reconstruction and replacement with a pulmonary autograft resulted in a lesser degree of postoperative subjective disturbance. Further research will be needed to clarify possible reasons for the observed differences.

\section{References}

1. Vahanian A, Baumgartner H, Bax J, Butchart E, Dion R, Filippatos G, et al. Guidelines on the management of valvular heart diseases: The Task Force on the Management of Valvular Heart Disease of European Society of Cardiology. Eur Heart J. 2007;28:230-68.

2. Ikonomidis JS, Kratz JM, Crumbley AJ 3rd, Stroud MR, Bradley SM, Sade RM, et al. Twenty-year experience with the St Jude Medical mechanical valve prosthesis. J Thorac Cardiovasc Surg. 2003;126:2022-31.

3. Hammermeister K, Sethi GK, Henderson WG, Grover FL, Oprian C, Rahimtoola SH. Outcomes 15 years after valve replacement with a mechanical versus a bioprosthetic valve: final report of the Veterans Affairs randomized trial. J Am Coll Cardiol. 2000;36:1152-8.

4. Chambers JC, Somerville J, Stone S, Ross DN. Pulmonary autograft procedure for aortic valve disease: long-term results of the pioneer series. Circulation. 1997;96:2206-14.

5. Takkenberg JJ, Klieverik LM, Schoof PH, van Suylen RJ, van Herwerden LA, Zondervan PE, et al. The Ross procedure: a systematic review and meta-analysis. Circulation. 2009;119:222-8.
6. David TE, Feindel CM. An aortic valve-sparing operation for patients with aortic incompetence and aneurysm of the ascending aorta. J Thorac Cardiovasc Surg. 1992;103:617-22.

7. Sarsam MA, Yacoub M. Remodeling of the aortic valve anulus. J Thorac Cardiovasc Surg. 1993;105:435-8.

8. Fraser CD Jr, Wang N, Mee RB, Lytle BW, McCarthy PM, Sapp SK, et al. Repair of insufficient bicuspid aortic valves. Ann Thorac Surg. 1994;58:386-90.

9. Langer F, Aicher D, Kissinger A, Wendler O, Lausberg H, Fries R, et al. Aortic valve repair using a differentiated surgical strategy. Circulation. 2004;110(11 Suppl. 1):II67-73.

10. Schäfers HJ, Aicher D, Langer F, Lausberg H. Preservation of the bicuspid aortic valve. Ann Thorac Surg. 2007;83:S740-5; discussion S785-90.

11. van Geldorp MW, Eric Jamieson WR, Kappetein AP, Ye J, Fradet GJ, Eijkemans MJ, et al. Patient outcome after aortic valve replacement with a mechanical or biological prosthesis: weighing lifetime anticoagulant-related event risk against reoperation risk. J Thorac Cardiovasc Surg. 2009;137:881-6. 886.e1-5.

12. Sedrakyan A, Hebert P, Vaccarino V, Paltiel AD, Elefteriades JA, Mattera J, et al. Quality of life after aortic valve replacement with tissue and mechanical implants. J Thorac Cardiovasc Surg. 2004;128:266-72.

13. Perchinsky M, Henderson C, Jamieson WR, Anderson WN Jr, Lamy A, Lowe N, et al. Quality of life in patients with bioprostheses and mechanical prostheses. Evaluation of cohorts of patients aged 51 to 65 years at implantation. Circulation. 1998;98(19 Suppl):II81-7.

14. Nötzold A, Hüppe M, Schmidtke C, Blömer P, Uhlig T, Sievers HH. Quality of life in aortic valve replacement: pulmonary autografts versus mechanical prostheses. J Am Coll Cardiol. 2001;37:1963-6.

15. Yacoub M, Gehle P, Chandrasekaran V, Birks E, Child A, Radley-Smith R. Late results of a valve-preserving operation in patients with aneurysms of the ascending aorta and root. J Thorac Cardiovasc Surg. 1998;115:1080-90.

16. Casselman FP, Gillinov AM, Akhrass R, Kasirajan V, Blackstone EH, Cosgrove DM. Intermediate-term durability of bicuspid aortic valve repair for prolapsing leaflet. Eur J Cardiothorac Surg. 1999;15:302-8.

17. Aicher D, Fries R, Rodionycheva S, Schmidt K, Langer F, Schäfers HJ. Aortic valve repair leads to a low incidence of valve-related complications. Eur J Cardiothorac Surg. 2010;37:127-32.

18. Minakata K, Schaff HV, Zehr KJ, Dearani JA, Daly RC, Orszulak TA, et al. Is repair of aortic valve regurgitation a safe alternative to valve replacement? J Thorac Cardiovasc Surg. 2004;127:645-53.

19. Smith HJ, Taylor R, Mitchell A. A comparison of four quality of life instruments in cardiac patients: SF-36, QLI, QLMI, and SEIQoL. Heart. 2000;84:390-4.

20. Snaith RP. The Hospital Anxiety And Depression Scale. Health Qual Life Outcomes. 2003;1:29.

21. Eifert GH, Thompson RN, Zvolensky MJ, Edwards K, Frazer NL, Haddad JW, et al. The cardiac anxiety questionnaire: development and preliminary validity. Behav Res Ther. 2000;38:1039-53.

22. Schmidtke C, Hüppe M, Berndt S, Nötzold A, Sievers HH. Quality of life after aortic valve replacement. Self-management or conventional anticoagulation therapy after mechanical valve replacement plus pulmonary autograft [in German]. $Z$ Kardiol. 2001;90:860-6.

23. Hoyer J, Eifert GH, Einsle F, Zimmermann K, Krauss S, Knaut M, et al. Heart-focused anxiety before and after cardiac surgery. J Psychosom Res. 2008;64:291-7.

24. Hinz A, Schwarz R. Anxiety and depression in the general population: normal values in the Hospital Anxiety and Depression Scale [in German]. Psychother Psychosom Med Psychol. 2001;51:193-200 